\title{
O Ensino das Soluções Aquosas de Electrólitos a Nível Secundário Parte I - Análise dos Manuais para o Ensino Secundário
}

\author{
VICTOR M.M. LOBO E ALCINDA L. RIBEIRO*
}

Na parte I faz-se uma análise aos manuais para o ensino secundário no que concerne ao estudo das soluções de electrólitos. Na parte II propõe-se um texto para o ensino dessa matéria para aquele nivel escolar.

\section{INTRODUÇÃO}

A condução eléctrica em soluções aquosas é um assunto que faz parte dos novos programas curriculares da disciplina de Físico-Química, que entraram em vigor no ano lectivo $1994 / 95$, sendo abordado pela primeira vez no $8^{\circ}$ ano do Ensino Básico e, posteriormente, no $10^{\circ}$ ano do Ensino Secundário.

No programa do $8^{\circ}$ ano da componente química desta disciplina encontram-se citados os seguintes objectivos:

“- Concluir através de experiências de condutibilidade eléctrica que há substâncias constituídas por átomos ou grupos de átomos portadores de carga eléctrica: os iões.

- Verificar através de experiências de migração de iões que num composto iónico há iões de carga positiva e de carga negativa."

No programa da componente de física da disciplina Físico-Química do $8^{\circ}$ ano de escolaridade este assunto é também abordado, como se constata pelos objectivos estabelecidos no respectivo programa:

“- Verificar experimentalmente a ocorrência de efeitos químicos, térmicos e magnéticos da passagem da corrente eléctrica e a sua relação com a variação da intensidade da corrente no circuito.

- Distinguir materiais que conduzem melhor a corrente do que outros (sólidos ou soluções)."

Uma das unidades temáticas do programa da componente de química da disciplina denominada "Ciências Físico-Químicas", do $10^{\circ}$ ano de escolaridade, intitula-se: “Um caso particular de equilíbrio: reacções de ácido-base". Neste capítulo são desenvolvidos quantitativamente os conceitos de força de um ácido e de uma base, extensão da ionização de ácidos e bases em solução aquosa. Nas orientações metodológicas do respectivo programa oficial é sugerido que estes conceitos sejam ensinados através da realização de experiências que envolvam o fenómeno da condução eléctrica em soluções aquosas de ácidos e de bases.

Pretendemos analisar a forma como manuais escolares de Química estão adaptados ao novo programa da disciplina "Físico-Química" do $10^{\circ}$ ano do Ensino Secundário, como abordam o fenómeno da condução eléctrica em soluções de electrólitos e como os conceitos são desenvolvidos. Apresentamos depois o texto que elaborámos para o tema da condutibilidade eléctrica em soluções aquosas.

O fenómeno da condução eléctrica em soluções de electrólitos aparece no programa de Química do $10^{\circ}$ ano de escolaridade não como um assunto novo, mas servindo de base ao desenvolvimento de novos conceitos, tais como: electrólito forte/fraco; grau de ionização de um electrólito; ácidos e base forte/fraco.

A análise feita aos manuais centrou-se principalmente sobre a forma como aqueles conceitos são desenvolvidos, alguns aspectos da linguagem utilizada e o tipo de actividades experimentais propostas. Para cada manual seguiu-se uma grelha de análise com os seguintes items:

\section{A - Desenvolvimento dos Conceitos}

\section{B - Actividades Experimentais Propostas}

1 - Finalidade das Experiências e Dispositivos Experimentais

2 - Procedimentos Experimentais

\section{C - Comentário à Linguagem e Simbologia Química Usadas}

Para cada um dos items da gretha analisados procedemos, sempre que considerámos indispensável, à transcrição de excertos dos vários manuais analisados.

\section{ANÁLISE A MANUAIS ESCOLARES}

\section{MANUAL 1}

\section{A - Desenvolvimento dos} Conceitos

\section{i) Electrólito}

“As substâncias que, ao dissolverem-se, são capazes de produzir iões, originando soluções condutoras, dizem-se electrólitos."

Neste manual é afirmado também que um electrólito pode ser um composto iónico, ou um composto molecular que apresente ligações covalentes polares. É feita a distinção entre o processo de ionização, no caso de um composto molecular, e o processo de dissociação, no caso dos compostos iónicos, sendo salientado o papel das interacções soluto-solvente em ambos os processos.

\section{ii) Electrólitos fortes e fracos}

Este manual começa por afirmar que quando substâncias, tais como o ácido azótico ou o sulfato de zinco, são dissolvidas em água, se verifica que a maioria das suas moléculas se dissociam em iões, sendo designadas por electrólitos fortes. Outras substâncias, como o ácido acético, encontram-se em solução pouco ionizadas, sendo designadas por electrólitos fracos.

São feitas distinções entre os electrólitos fortes e fracos, como se pode constatar pelos excertos abaixo transcritos, sendo referido: (1) o papel das interacções iónicas na extensão da ionização dos electrólitos fortes em soluções aquosas muito diluídas e concentradas; (2) o equilíbrio existente nas soluções aquosas de electrólitos fracos entre as moléculas de soluto não ionizadas e os respectivos iões.

"Uma substância que, ao dissolver-se, se ioniza em grande extensão, quase totalmente, diz-se um electrólito forte. Os electrólitos fortes, em soluções extremamente dilu- 
ídas, encontram-se mesmo completamente ionizados. À medida que a concentração aumenta, os iões interactuam entre si e a ionização, embora extensa, deixa de ser completa."

"Existem também electrólitos (...) que, em solução, se encontram muito pouco ionizados. A ionização está limitada pelo processo inverso: do choque entre os ióes resultam moléculas do soluto, as quais passam a existir em solução."

\section{iii) Grau de ionização}

Neste manual é referido que uma forma de determinar experimentalmente o grau de ionização de um electrólito, numa dada solução, é através da medição da condutibilidade eléctrica da respectiva solução.

É, também, mencionado que a condutibilidade eléctrica de uma solução aumenta com o grau de ionização do electrólito, visto que "os iōes se tornam mais numerosos". É ainda referido que o grau de ionização varia com a natureza do electrólito e, para um dado electrólito, varia com a concentração e a temperatura.

\section{tais}

\section{B - Actividades Experimen-}

1 - Finalidade das Experiências e Dispositivos Experimentais

É sugerida a realização de uma experiência com o objectivo de comparar a força de três ácidos: clorídrido, sulfúrico e fosfórico. O esquema de montagem consta de uma tina com dois eléctrodos, onde se lançam as soluções a estudar, uma lâmpada, um reóstato, e um elemento gerador de corrente. tais

2 - Procedimentos Experimen-

Para a realização da referida experiência são dadas instruções para o uso de soluções aquosas de três ácidos em estudo, com igual concentração, e para o registo do número de gotas de cada solução que terão de ser adicionadas a um igual volume de água, para que a lâmpada incor- porada no circuito eléctrico acenda.

A experiência em questão estabelece a comparação entre a força de dois electrólitos fortes, sendo um monoprótico e o outro diprótico, e de um electrólito fraco, triprótico. Quando ionizados, estes electrólitos originam, nas respectivas soluçōes aquosas, espécies iónicas com cargas eléctricas diferentes, sendo o electrólito mais fraco o que produz iões com cargas eléctricas mais elevadas. Por conseguinte, nesta experiência, estão em jogo dois factores (o número de iões e a quantidade de carga eléctrica) que influenciam a condutibilidade eléctrica de uma solução, mas que actuam em sentidos opostos em cada uma das três soluções consideradas. Assim, o electrólito que possui a ionização menos extensa (ácido fosfórico) é o que origina iōes com maior carga eléctrica. Consideramos, pois, que a não ser que o professor na sala de aula proceda a uma descriminação das variáveis que influenciam a condutibilidade eléctrica de soluções, assim como a explicação da finalidade do reóstato inserido no circuito eléctrico, a interpretação dos resultados de experiências semelhantes a esta poderá tornar-se difícil para o aluno.

O uso de uma lâmpada como indicador da maior ou menor condutibilidade eléctrica de uma solução parece-nos pouco adequado, embora reconhecamos que seja bastante elucidativo e acarrete baixos custos.

\section{C - Comentário à Linguagem e Simbologia Química Usadas}

Não gostamos do conceito de electrólito apresentado e propomos o seguinte:

"Electrólitos sāo substâncias que, ao dissolverem-se num dado solvente, produzem uma solução com maior condutibilidade eléctrica que o solvente puro. São exemplos o cloreto de sódio, $\mathrm{NaCl}$ (um sólido a temperatura ambiente), o ácido acético puro, $\mathrm{CH}_{3} \mathrm{COOH}$ (um líquido), ou o ácido clorídrico puro, $\mathrm{HCl}$ (um gás).

Não confundir electrólito (o composto químico puro) com solu- ção electrolítica (o resultado da adição do composto ao solvente)."

Alternativamente, poder-se-ia dizer, de forma mais abreviada,

“Electrólitos são substâncias que aumentam à condutibilidade eléctrica do solvente."

É óbvio que o texto teria de garantir que com esta forma abreviada $o$ aluno entendesse bem o equivalente à primeira forma citada.

Dar este conceito de electrólito tem, sobre o que o manual 1 apresenta, a vantagem de ser fenomenológico (e algo que o aluno pode observar facilmente). O manual 1 , ao dizer "...produzir iões ..." faz recurso a algo que é já uma interpretação humana dos fenómenos observados, com todos os inconvenientes que tal apresenta. Esta observação aplica-se a vários outros aspectos da linguagem usada: há um excessivo uso de conceitos que são uma interpretação humana, quando se poderia e deveria usar vocábulos que se prendem com os fenómenos observados. Depois, e tornando bem claro tratar-se de interpretação dos fenómenos (de teorias, como alguns dizem), apresentar-se-iam os vocábulos resultantes dessa interpretação.

Não nos parece necessário ter a preocupação, para alunos do secundário, de estender estes conceitos aos chamados "electrólitos sólidos", a sais fundidos, etc. Se eles entenderem bem os conceitos que se prendem com as soluções aquosas de electrólitos, facilmente, um dia, os poderão generalizar para outras áreas. Acreditamos que mais vale ensinar pouco, mas de maneira a criar conceitos claros e úteis na mente do aluno.

Aquando da introdução do conceito de electrólito, e ao introduzir os processos de ionização e de dissociação de alguns compostos iónicos e moleculares, respectivamente, são apresentadas para dois electrólitos as respectivas equações químicas que traduzem estes dois processos da seguinte forma:

$\mathrm{NaCl}(\mathrm{s})+\mathrm{aq}=\Rightarrow \mathrm{Na}^{+}(\mathrm{aq})+\mathrm{Cl}^{-}(\mathrm{aq})$

$\mathrm{HCl}(\mathrm{g})+\mathrm{aq}=\Rightarrow \mathrm{H}^{+}(\mathrm{aq})+\mathrm{Cl}^{-}(\mathrm{aq})$ 
Consideramos incorrecta a escrita de "aq", tal como aparece no lado correspondente às substâncias reagentes, uma vez que esta simbologia é usada para indicar o estado físico de uma substância, reagente ou produto de uma reacção química, e nunca isoladamente como aparece neste caso. Esta forma de escrita gera confusões para o aluno, já que poderá pensar que estes símbolos são usados para representar a água.

Neste manual aparece uma incorrecção que é designar o ácido clorídrico por ácido clórico.

\section{MANUAL 2}

\section{A - Desenvolvimento dos Conceitos}

\section{i) Electrólito}

“Uma substância que, fundida ou dissolvida, conduz a corrente eléctrica devido ao fluxo dos seus iões é um condutor iónico, designando-se também por electrólito, e as suas soluções são soluções electrolíticas."

\section{ii) Processo da Condução Eléctrica em So- luções}

Neste manual aparece a seguinte explicação para o fenómeno da condução eléctrica em soluções iónicas: "Submetidos a um campo eléctrico, os iões movem-se de uma forma orientada - os catiões para o polo negativo, os aniões para o polo positivo - conduzindo a corrente eléctrica."

\section{B - Actividades Experimentais}

\section{1 - Finalidade das Experiências e Dispo- sitivos Experimentais}

Neste manual é apresentada uma experiência cuja finalidade é testar o carácter electrolítico de duas soluções de cloreto de hidrogénio em dois solventes diferentes, e daí concluir sobre a ocorrência da ionização do $\mathrm{HCl}$ em cada um dos casos. O teste da condutibilidade eléctrica das duas soluções é feito usando o dispositivo experimental similar ao do manual 1 .

\section{C - Comentário à Linguagem e Simbologia Química Usadas}

Os comentários anteriormente feitos aplicam-se, em parte, a este manual. Não achamos apropriado dizer que o "electrólito ... conduz a corrente eléctrica ..." e dizer-se que "...é devido ao fluxo ...". Achamos melhor a definição fenomenológica atrás citada (só depende de factos observados, não de teorias) eventualmente complementada com uma dada interpretação, e agora sim, recorrendo a modelos sobre a constituição da matéria.

Quanto ao modelo apresentado para explicar a propagação de um campo electromagnético num condutor metálico ou electrolítico, haveria que procurar uma certa coordenação com os manuais da disciplina de "Física". É que o modelo do "fluxo" de cargas pode deixar os alunos muito confusos ao pensarem na propagação do campo no caso da corrente alternada, efectivamente o que mais nos interessa nos estudos de condutibilidade. Supomos que não seria difícil dar aos alunos a ideia de propagação de um campo sem necessidade de fluxo de matéria, talvez recorrendo à experiência das "bolas de Newton", onde a esfera de aco terminal salta por impacto na inicial, sem movimentação das intermediárias.

\section{MANUAL 3}

\section{A - Desenvolvimento dos Conceitos}

\section{i) Electrólito}

"Chama-se electrólito a uma substância que, no estado líquido ou em solução, conduz a corrente eléctrica (movimento de iões)."

\section{B - Actividades Experimentais}

\section{1 - Finalidade das Experiências e} Dispositivos Experimentais

Neste manual é sugerida uma experiência com o objectivo de demonstrar que o processo da condução eléctrica em soluções iónicas en- volve o movimento, em sentidos opostos, dos iões positivos e negativos.

É sugerida neste manual a realização de experiências, usando o dispositivo similar ao do manual 1, com o objectivo de classificar algumas substâncias em electrólitos ou não electrólitos, e classificar os electrólitos em fortes e fracos.

A intensidade do brilho da lâmpada, inserida nos circuitos eléctricos, é usada como critério para comparar a força dos electrólitos.

\section{C - Comentário à Linguagem e Simbologia Química Usadas}

Alguns comentários anteriores são aplicáveis.

No seguimento das experiências propostas são estabelecidas neste manual conclusões como as que a seguir se transcrevem:

“As soluções do ácido clorídrico e do cloreto de sódio conduzem a corrente eléctrica muito melhor do que o ácido acético diluído (a lâmpada brilha intensamente) — são electrólitos fortes."

"O ácido acético diluído é um electrólito fraco."

Consideramos que, e uma vez que anteriormente neste manual se pôs em evidência a existência de iões num meio condutor, poderia ser estabelecida uma relação entre a intensidade do brilho da lâmpada e o número de iões presentes na solução. Assim, os resultados das experiências realizadas poderiam ser explicados em termos do maior ou menor número de iões presentes e daí ser concluído que medidas de condutibilidade eléctrica de uma solção aquosa de um electrólito podem ser usadas para quantificar a extensão de ionização desse electrólito em água.

Relativamente à segunda afirmação, consideramos incorrecto afirmar que o ácido acético diluído é um electrólito fraco. O ácido acético é que é um electrólito fraco e não a respectiva solução aquosa. Além disso, e com rigor, não existe ácido acético diluído, tal como também é 
referido neste manual; o que existem são soluções diluídas de um electrólito.

Apesar de serem usadas na linguagem corrente estas designações, consideramos que num manual escolar elas devem ser evitadas.

A directiva da IUPAC de se substituir a tradicional designação de "número de moles" por "quantidade de matéria (ou substância)" talvez devesse ser extensiva ao "número de iões". Contudo, não entraríamos aqui com essas considerações.

\section{MANUAL 4}

\section{A - Desenvolvimento dos Conceitos}

\section{i) Electrólito}

“Compostos (...) que em solução aquosa, ou fundidos, conduzem bem a corrente eléctrica, dizem-se electrólitos."

"Os compostos que originam iões livres, e que tornam as soluções boas condutoras, dizem-se electrólitos."

Os comentários que fizemos ao manual 1 aplicam-se também neste caso.

Consideramos também que não é feliz a designação "iões livres", uma vez que os iões em qualquer solução estão sempre rodeados por moléculas de solvente, as quais influênciam os seus movimentos através da solução, quando sujeitos a um campo eléctrico.

ii) É fornecida uma explicação para o fenómeno da condução eléctrica em meios iónicos nos seguintes termos:

"A corrente eléctrica é um movimento orientado de cargas eléctricas; no caso das soluções, o movimento ordenado dos iões é o responsável pela corrente."

Conforme já anteriormente citámos, entendemos ser melhor dizer algo como "... corrente eléctrica pode ser explicada como sendo um movimento ...".

$\mathrm{O}$ aluno deve entender bem a distinção entre fenómenos realmente observados e as explicações (as "teo- rias") dadas para interpretar esses fenómenos.

\section{B - Actividades Experimentais}

1 - Finalidade das Experiências e Dispositivos Experimentais

É apresentada uma sugestão para a realização de uma experiência cujos objectivos são a "apreciação da condutibilidade eléctrica de soluções de $\mathrm{HCl}$ em água e em tricloroetano" e a "observação da boa ou má condutibilidade eléctrica de uma solução de ácido acético".

\section{PROCEDIMENTOS EXPERIMENTAIS}

Este é o único manual em que no esquema da montagem do circuito eléctrico proposto para testar a condutibilidade eléctrica de soluções, aparece juntamente com uma lâmpada um miliamperímetro, com a especificação da amplitude da sua escala. Deste modo, mesmo que a intensidade da corrente eléctrica que percorre o circuito não seja suficientemente elevada para acender a lâmpada, o miliamperímetro detectará a sua passagem.

É também salientado neste manual (em nota de rodapé) que a distância entre os eléctrodos e a porção destes mergulhada na solução devem ser mantidas constantes para todas as experiências. É o único manual em que são indicadas estas precauções.

\section{C - Comentário à Linguagem e Simbologia Química Usadas}

Imediatamente a seguir à definição de electrólito (segunda afirmação acima descrita) é feita a seguinte afirmação:

"A carga negativa de uns iões (aniões) é igual, em módulo, à carga positiva dos outros iões (catiões)."

Por um lado, consideramos inoportuna a introdução desta afirmação no seguimento da noção de electrólito e, por outro lado, isto só é verdadeiro para um certo tipo de electrólitos: os electrólitos do tipo simétrico. Os autores talvez pretendessem afirmar que numa solução de electrólito é verificada a condição da electroneutralidade. Se a afirmação fosse aplicada neste sentido, então deveria ser substituída por: "Numa solução de electrólito, a carga eléctrica positiva total, devido aos catiões, é igual em módulo à carga eléctrica negativa total, devida aos aniões, sendo a solução electricamente neutra."

Alguns comentários feitos à linguagem dos anteriores manuais também aqui têm oportunidade, bem como nos manuais seguidamente referidos, sendo contudo desnecessário voltar a referir o assunto.

MANUAL 5

\section{A - Desenvolvimento dos Conceitos}

Neste manual não é dada a noção de electrólito nem são feitas considerações àcerca do fenómeno da condução eléctrica em soluções de electrólitos. Contudo, a classificação de ácidos e de bases em fortes ou fracos é estabelecida com base em considerações àcerca da condutibilidade eléctrica das respectivas soluções aquosas.

\section{B - Actividades Experimentais}

1 - Finalidade das Experiências e Dispositivos Experimentais

Num subcapítulo deste manual, intitulado "Força de ácidos e bases", é apresentado um esquema de uma montagem similar aos anteriormente citados. A finalidade da experiência é verificar que uma solução aquosa de cloreto de hidrogénio é "muito melhor condutora da corrente eléctrica" do que soluções aquosas de ácido acético e de amoníaco, de iguais concentrações. Deste modo, e concluído que o $\mathrm{HCl}$ é um ácido forte, o $\mathrm{CH}_{3} \mathrm{COOH}$ é um ácido fraco, e o $\mathrm{NH}_{3}$ é uma base fraca. 


\section{2 - Procedimentos Experimentais}

Neste manual é referido que os volumes de ácido clorídrico, de ácido acético e da solução aquosa de amoníaco, a usar nas experiências acima mencionadas, devem ser iguais e as soluções devem ter igual concentração.

Analisando este procedimento experimental constata-se que é tido em atenção o facto de que o estabelecimento das forças relativas dos três electrólitos, com base na comparação dos valores registados da intensidade da corrente em cada um dos casos, só é possível se for estabelecido um padrão comum. Assim, são usados volumes iguais de soluções aquosas de electrólito com igual concentração.

Uma vez que quando uma molécula de qualquer um dos três electrólitos considerados, ao ser ionizada, produz o mesmo número de iões com cargas eléctricas iguais, então os valores da intensidade da corrente registada em cada um dos casos serão, de facto, proporcionais ao número de iões presentes em cada uma das soluções. Assim, a comparação desses valores poderá ser usada para estabelecer a extensão relativa da ionização dos três electrólitos e, por conseguinte, as suas forças relativas.

\section{MANUAL 6}

\section{A - Desenvolvimento dos Conceitos}

Neste manual não é feita qualquer referência ao fenómeno da condução eléctrica em soluções, nem é apresentada qualquer experiência que faça uso deste fenómeno. É feita unicamente uma referência a esta propriedade das soluções quando é dada a noção de eletrólito, como se pode constatar pela afirmação que se segue:

"Chamam-se electrólitos às substâncias que se ionizam em solução aquosa. A condutibilidade eléctrica de uma solução de electrólito é tanto maior quanto mais forte for o electrólito."
MANUAL 7

\section{A - Desenvolvimento dos Conceitos}

Tal como no manual 6, também neste não é feita qualquer referência ao fenómeno da condução eléctrica em soluções iónicas. Contudo, com o objectivo de introduzir a noção de uma substância que funciona como um ácido em presença da água, é mostrado um circuito eléctrico no qual uma lâmpada está acesa. Pressupõe-se, pois, que o aluno interprete tal facto pela formação de iões quando tal substância é adicionada à água.

\section{B - Actividades Experimentais}

A experiência proposta permite demonstrar ao aluno, após este ter adquirido conhecimentos sobre reacções de ácido-base e de titulações, e tendo conhecimento de que a condutibilidade de uma solução depende da quantidade de iões presentes, que antes de ser atingido o ponto de equivalência há uma diminuição do número de iões na mistura e, após o ponto de equivalência, há um aumento do número de iões presentes. Este manual é o único que utiliza a condutibilidade eléctrica de soluções com esta finalidade.

\section{MANUAL 8}

\section{A - Desenvolvimento dos Conceitos}

\section{i) Força de ácidos}

É referido que os ácidos são electrólitos e, consequentemente, conduzem a corrente eléctrica quando em solução aquosa.

\section{ii) Condutibilidade Eléctrica e Grau de Ionização \\ É mencionado que a condutibi-} lidade eléctrica de uma solução depende do número de iões nela presentes e, por conseguinte, pode ser usada para estabelecer se um electrólito em água está ionizado em grande ou pequena extensão.
Já anteriormente comentámos este tipo de abordagem.

\section{B - Actividades Experimentais \\ 1 - Finalidade das Experiências e Dispositivos Experimentais}

Nas experiências propostas são usadas soluções aquosas dos dois ácidos com igual concentração. Neste manual é chamada a atenção para o facto de soluções de electrólitos diferentes, contendo quantidades equimolares de ácido, apresentarem condutibilidades eléctricas diferentes.

Nesta experiência o brilho da lâmpada inserida no circuito é também usado para comparar as condutibilidades das duas soluções.

\section{CONCLUSÃO}

Da análise feita a estes oito manuais escolares constata-se que a linguagem utilizada nem sempre é a mais adequada; na parte II são apresentadas as linhas gerais da nossa proposta de um texto para o ensino desta matéria.

\footnotetext{
- Departamento de Química, Universidade de Coimbra 3000 Coimbra, Portugal
}

REFERÊNCIAS

MANUAL 1 - Concio, M.H., "Química $10^{\circ}$ Ano", Ediçǒes Asa.

MANUAL 2 - Ferreira, A. e Camôes, F., "Química 10" Ano", Texto Editora.

MANUAL 3 - Faria, A.M.M., Mota, I., Domingues, L., Ribeiro, L. e Ribeiro, M.I., "Química $10^{\circ}$ Ano", Raiz Editora.

MANUAL 4 - Correa, C., Nunes, A. e Almeida, N., "Quimica $10^{\circ}$ Ano", Porto Editora.

MANUAL 5 - Fernandes, M.B. e Graca, O.C., "Química $10^{\circ}$ Ano", Lisboa Editora.

MANUAL 6 - Santos, A.M. e Teodoro, V.D., "Química $10^{\circ}$ Ano", Didáctica Editora.

MANUAL 7 - Gil, V.M.S., "Química $10^{\circ}$ Ano", Plátano Editora.

MANUAL 8 - Lourenço, M.G. e Tadeu, V., "Química $10^{\circ}$ Ano", Porto Editora. 